\title{
Comparison of conservative treatment versus transcatheter arterial embolisation for the treatment of spontaneously ruptured hepatocellular carcinoma
}

\author{
Kohei Shinmura ${ }^{1 A, D, E, F}$, Young Ho Choi ${ }^{2 B}$, Masashi Shimohira ${ }^{3 B}$, Yasutaka Baba ${ }^{4 A, B, E}$, Shunichiro Ikeda ${ }^{1 A, B}$, \\ Sadao Hayashi ${ }^{1 B}$, Yuta Shibamoto ${ }^{3 B}$, Chihaya Koriyama ${ }^{5 C}$, Takashi Yoshiura ${ }^{1 \mathrm{~A}, \mathrm{E}}$ \\ 'Department of Radiology, Graduate School of Medical and Dental Sciences, Kagoshima University, Kagoshima, Japan \\ 2Department of Radiology, The SMG-SNU Boramae Medical Centre, Seoul, Korea \\ ${ }^{3}$ Department of Radiology, Nagoya City University Hospital, Nagoya, Japan \\ ${ }^{4}$ Yasutaka Baba, Department of Radiology, Hiroshima University Hospital, Hiroshima, Japan \\ ${ }^{5}$ Department of Epidemiology and Preventive Medicine, Kagoshima University, Kagoshima, Japan
}

\section{Abstract}

Purpose: To elucidate the prognostic factors in the spontaneous rupture of hepatocellular carcinoma (HCC) and to determine whether transcatheter arterial embolisation (TAE) is associated with better prognosis compared to conservative treatment.

Material and methods: A retrospective multicentre study was conducted involving 71 patients with spontaneous rupture of HCC. A conservative treatment group (Cons T group) included 20 patients, while a transcatheter arterial embolisation group (TAE group) included 51 patients.

Results: The median survival time (MST) in the Cons T group was only 16 days and the survival rate was $39 \%$ at one month, whereas the MST in the TAE group was 28 days and the one month survival rate was $63 \%$. However, there is no statistically significant difference in the overall survival between Cons T and TAE groups $(p=0.213)$. Multivariable analysis identified only the presence of distant metastasis as an independent prognostic factor $(p=0.023)$. A subanalysis including patients without distant metastasis showed that the presence of portal vein tumour thrombosis was a significant prognostic factor $(p=0.015)$.

Conclusions: Distant metastasis appears to be a prognostic factor in spontaneous rupture of HCC. In cases without distant metastasis, portal vein tumour thrombosis could influence the prognosis. Our data failed to prove any benefit of TAE as the primary management.

Key words: hepatocellular carcinoma, rupture, prognosis, transcatheter arterial embolization (TAE).

\section{Introduction}

The spontaneous rupture of hepatocellular carcinoma (HCC) is a rare but life-threatening presentation of this disease and cause of death in $6.4 \%$ of such cases in Japan [1]. The affected patients frequently have poor liver function due to liver cirrhosis and advanced tumour stage, and previous reports showed that the one-month mortality rate ranged from $28 \%$ to $71 \%$ with a median survival period of 4 to 32 weeks [2-8]. The spontaneous rupture of HCC has been treated with several different methods such as conservative treatment (Cons $\mathrm{T}$ ) and transcatheter arterial

Correspondence address:

Kohei Shinmura, Department of Radiology, Graduate School of Medical and Dental Sciences, Kagoshima University 8-35-1 Sakuragaoka, Kagoshima,

890-8544 Japan, phone: +81-99-275-5417, fax: +81-99-265-1106, e-mail: k2406593@kadai.jp

Authors' contribution:

A Study design · B Data collection · C Statistical analysis · D Data interpretation · E Manuscript preparation · F Literature search · G Funds collection 
embolisation (TAE). However, due to its relative rarity and difficulty in conducting prospective comparisons, there is little consensus on the appropriate management and prognostic factors. Therefore, we introduced a multi-centre retrospective study to elucidate the prognostic factors in the spontaneous rupture of HCC and to determine whether TAE is associated with better prognosis than Cons $\mathrm{T}$.

\section{Material and methods}

\section{Study population and clinical data}

This multicentre retrospective study was approved by the Institutional Review Board of each participating institution, and the need for informed consent acquisition was waived.

We retrospectively analysed pooled data obtained from the clinical and radiological records of 71 consecutive patients (56 males and 15 females; age range 32-86 years, mean 65.1 years) with spontaneous rupture of HCC, who were treated between October 1989 and December 2011 in three different sites in two countries: hospital A (15 patients), B (43 patients), and C (13 patients). Cause of liver damage (hepatitis type), Child-Pugh classification (A, B, or C), presence/absence of hepatic encephalopathy, ascites, shock vital (systolic blood pressure $<80 \mathrm{mmHg}$ ), portal vein tumour thrombosis, distant metastasis, and past history of HCC treatment, tumour size (maximum diameter on axial CT image), tumour morphology (massive or diffuse), serum $\alpha$-fetoprotein (AFP), blood chemistry data (serum albumin, total bilirubin, aspartate aminotransferase [AST], alanine transaminase [ALT], blood urea nitrogen [BUN], and creatinine), haemoglobin, prothrombin time, primary management (TAE or conservative), and secondary management (TAE or surgery or none) were recorded.

\section{Treatment methods}

Attending physician assessed patients' states and conducted the treatment method (TAE or Cons T) and obtained consent from the patient or patient's family. TAE was approached from femoral artery with the Seldinger technique. Angiographic catheter was inserted in the hepatic artery and contrast agent was injected, so that branches of bleeding hepatic artery were identified. As an embolic material, gelatin sponge that was cut into small cubes of approximately 1-2 $\mathrm{mm}^{3}$ in size was injected into bleeding arteries. The embolic procedure was finished because we could confirm the stopping of bleeding by angiography. In conservative treatment, a haemostatic agent and/or pain relief drug was intravenously infused.

\section{Statistical analyses}

The $\chi^{2}$ test for independence or the Fisher exact test was used for comparison of the two groups. To determine factors influencing overall survival, a univariate analysis was performed using the Kaplan-Meier method and a logrank test. The survival period was defined as the length of time from the onset of the spontaneous rupture of HCC until death. Subsequently, to identify independent prognostic factors, multivariable analysis was performed using the Cox proportional hazard model from which hazard ratios with their confidence intervals and $p$ values were reported. $P<0.05$ was considered statically significant for all analyses. All statistical analyses were performed using StatView; SAS software.

\section{Results}

The patients' characteristics are shown in Table 1. Cause of liver damage was alcoholic in seven patients (10\%), hepatitis B in 28 patients (39\%), hepatitis C in 18 patients (25\%), and non-B non-C in six patients (8\%). Eight patients (11\%) were in Child-Pugh A class, 34 (48\%) in B class, and 22 (31\%) in C class. Five patients (7\%) had hepatic encephalopathy. Fifty-nine patients $(83 \%)$ had ascites. Ten patients (16\%) had shock vital at the time of admission. Mean tumour size of HCCs was $7.5 \mathrm{~cm}$. Forty-two patients (59\%) had past history of HCC treatment. Mean follow-up period was 106.8 days (range 0-2972 days).

Conservative treatment (Cons T group) was employed as the primary management in 20 patients (28\%), while transcatheter arterial embolisation (TAE group) was performed in the remaining 51 patients (72\%). Hepatic encephalopathy was more frequent in the Cons $\mathrm{T}$ group than in the TAE group $(p=0.001)$. In addition, serum total bilirubin was significantly higher $(p=0.012)$ and prothrombin time was significantly shorter $(p=0.003)$ in the Cons T group than in the TAE group. No significant difference was found in the other variables between the two groups.

The median survival time (MST) was 22 days, and onemonth mortality rate was $56 \%$ in all patients. MST in the Cons T group was 16 days and the survival rate was poor: $75 \%$ at seven days, $60 \%$ at 14 days, $39 \%$ at one month, and $22 \%$ at three months. On the other hand, MST in TAE group was 28 days and the survival rate was $83 \%$ at seven days, $73 \%$ at 14 days, $63 \%$ at one month, $27 \%$ at three months, $18 \%$ at 12 months, and $18 \%$ at 24 months. However, there was no statistically significant difference in the survival rate between the Cons T and TAE groups $(p=0.213)$ (Table 2, Figure 1). Factors associated with significantly lower overall survival included being female $(p=0.006)$, higher ChildPugh grade $(p=0.012)$, presence of hepatic encephalopathy $(p<0.001)$, presence of portal vein tumor thrombosis $(p<0.001)$, presence of distant metastasis $(p=0.005)$, presence of past history of HCC ( $p=0.049)$, lower serum albumin $(p=0.018)$, higher total bilirubin $(p<0.001)$, and longer prothrombin time $(p=0.017)$ (Table 2$)$.

A multivariable analysis admitted factors that were shown to be significant in the univariate analysis. Hepatic encephalopathy, serum total bilirubin, albumin, and 
Table 1. Patient characteristics of the analysed cohort and comparisons between conservative treatment group (Cons $\mathrm{T}$ ) and transcatheter arterial embolisation (TAE) groups

\begin{tabular}{|c|c|c|c|c|}
\hline Variables & Total & Cons T group & TAE group & $p$ value \\
\hline Patients, $n(\%)$ & 71 & $20(28)$ & $51(72)$ & \\
\hline Age (y) & $65.1(13.3)$ & $68.2(10.7)$ & $63.8(14.1)$ & $0.378 \mathrm{NS}$ \\
\hline \multicolumn{4}{|l|}{ Sex, $n(\%)$} & \multirow[t]{3}{*}{$0.621 \mathrm{NS}$} \\
\hline Male & $56(79)$ & $15(75)$ & $41(80)$ & \\
\hline Female & $15(21)$ & $5(25)$ & $10(20)$ & \\
\hline \multicolumn{4}{|l|}{ Cause of liver damage, $n$ (\%) } & \multirow[t]{5}{*}{$0.767 \mathrm{NS}$} \\
\hline Alcohol & $7(10)$ & $1(5)$ & $6(12)$ & \\
\hline Hepatitis B & $28(39)$ & $7(35)$ & $21(41)$ & \\
\hline Hepatitis C & $18(25)$ & $4(20)$ & $14(27)$ & \\
\hline Non-B, non-C & $6(8)$ & $1(5)$ & $5(10)$ & \\
\hline \multicolumn{4}{|l|}{ Child-Pugh classification, $n(\%)$} & \multirow[t]{4}{*}{0.786 NS } \\
\hline A & $8(11)$ & $2(10)$ & $6(12)$ & \\
\hline B & $34(48)$ & $8(40)$ & $26(51)$ & \\
\hline$C$ & $22(31)$ & $7(35)$ & $15(29)$ & \\
\hline \multicolumn{4}{|l|}{ Hepatic encephalopathy, $n(\%)$} & \multirow[t]{2}{*}{0.002} \\
\hline Present & $5(7)$ & $4(20)$ & $1(2)$ & \\
\hline \multicolumn{4}{|l|}{ Ascites, $n(\%)$} & \multirow[t]{2}{*}{$0.209 \mathrm{NS}$} \\
\hline Present & $59(83)$ & $15(75)$ & $44(86)$ & \\
\hline \multicolumn{4}{|l|}{ Shock vital, $n(\%)$} & \multirow[t]{2}{*}{$0.719 \mathrm{NS}$} \\
\hline Present & $16(22)$ & $4(20)$ & $12(23)$ & \\
\hline Tumour size $(\mathrm{cm})$ & $7.5(3.9)$ & $7.2(0.8)$ & $7.6(4.1)$ & 0.842 NS \\
\hline \multicolumn{4}{|l|}{ Tumour morphology, $n(\%)$} & \multirow[t]{3}{*}{$0.778 \mathrm{NS}$} \\
\hline Massive & $34(47)$ & $6(30)$ & $28(54)$ & \\
\hline Diffuse & $14(19)$ & $5(25)$ & $9(17)$ & \\
\hline \multicolumn{4}{|c|}{ Portal vein tumour thrombosis, $n(\%)$} & \multirow[t]{2}{*}{$0.326 \mathrm{NS}$} \\
\hline Present & $19(27)$ & $7(35)$ & $12(24)$ & \\
\hline \multicolumn{4}{|l|}{ History of HCC treatment, $n(\%)$} & \multirow[t]{2}{*}{$0.089 \mathrm{NS}$} \\
\hline Present & $42(59)$ & $15(75)$ & $27(53)$ & \\
\hline \multicolumn{4}{|l|}{ Secondary management, $n(\%)$} & \multirow[t]{4}{*}{$0.083 \mathrm{NS}$} \\
\hline TAE & $6(8)$ & $0(0)$ & $6(12)$ & \\
\hline Surgery & $1(1)$ & $1(5)$ & $0(0)$ & \\
\hline None & $62(87)$ & $19(95)$ & $43(84)$ & \\
\hline Serum albumin $(g / l)$ & $2.85(0.64)$ & $2.81(0.55)$ & $2.87(0.68)$ & $0.720 \mathrm{NS}$ \\
\hline Serum total bilirubin $(\mu \mathrm{mol} / \mathrm{l})$ & $3.47(5.08)$ & $5.89(8.62)$ & $2.51(2.39)$ & 0.012 \\
\hline Serum AFP (ng/ml) & $47821(113213)$ & $7721(14084)$ & $58132(125013)$ & $0.238 \mathrm{NS}$ \\
\hline AST (U/I) & $197.8(262.5)$ & $205.0(218.9)$ & $195.0(278.9)$ & $0.889 \mathrm{NS}$ \\
\hline $\operatorname{ALT}(\mathrm{U} / \mathrm{l})$ & $114.7(240.7)$ & $96.6(118.5)$ & $121.4(273.4)$ & 0.705 NS \\
\hline Haemoglobin (g/dl) & $8.99(2.49)$ & $9.16(2.53)$ & $8.92(2.50)$ & $0.726 \mathrm{NS}$ \\
\hline Prothrombin time (s) & $32.8(24.6)$ & $18.7(15.1)$ & $37.8(25.0)$ & 0.003 \\
\hline BUN (mg/dl) & $24.2(15.7)$ & $26.8(20.4)$ & $23.3(13.7)$ & 0.411 NS \\
\hline CRE (mg/dl) & $1.43(1.47)$ & $1.23(0.79)$ & $1.50(1.65)$ & $0.524 \mathrm{NS}$ \\
\hline
\end{tabular}

Cons T - conservative treatment, TAE - transcatheter arterial embolization, NS - not significant, AFP - $\alpha$-fetoprotein, AST - aspartate aminotransferase, ALT - alanine aminotransferase Continuous variables are indicated in the mean (SD) 
Table 2. Univariate analysis searching for factors influencing overall survival

\begin{tabular}{|c|c|c|c|}
\hline Variables & Number & Median survival (day) & $p$ value (log-rank) \\
\hline \multicolumn{3}{|l|}{ Age } & \multirow[t]{4}{*}{0.316 NS } \\
\hline$\leq 58$ & 24 & 17 & \\
\hline$>58$ and $<73$ & 22 & 25 & \\
\hline$\geq 73$ & 25 & 20 & \\
\hline \multicolumn{3}{|l|}{ Sex } & \multirow[t]{3}{*}{0.006} \\
\hline Male & 56 & 25 & \\
\hline Female & 15 & 10 & \\
\hline \multicolumn{3}{|l|}{ Institution } & \multirow[t]{4}{*}{$0.855 \mathrm{NS}$} \\
\hline$A$ & 15 & 20 & \\
\hline B & 43 & 17 & \\
\hline$C$ & 13 & 28 & \\
\hline \multicolumn{3}{|l|}{ Primary management } & \multirow[t]{3}{*}{$0.213 \mathrm{NS}$} \\
\hline TAE & 51 & 28 & \\
\hline Cons T & 20 & 16 & \\
\hline \multicolumn{3}{|l|}{ Child-Pugh classification } & \multirow[t]{4}{*}{0.012} \\
\hline$A$ & 8 & 30 & \\
\hline B & 34 & 22 & \\
\hline$C$ & 22 & 11 & \\
\hline \multicolumn{3}{|l|}{ Hepatic encephalopathy } & \multirow[t]{3}{*}{$<0.001$} \\
\hline Absent & 64 & 25 & \\
\hline Present & 5 & 1 & \\
\hline \multicolumn{3}{|l|}{ Ascites } & \multirow[t]{3}{*}{$0.988 \mathrm{NS}$} \\
\hline Absent & 11 & 17 & \\
\hline Present & 59 & 22 & \\
\hline \multicolumn{3}{|l|}{ Shock vital } & \multirow[t]{3}{*}{0.105 NS } \\
\hline Absent & 54 & 28 & \\
\hline Present & 16 & 10 & \\
\hline \multicolumn{3}{|l|}{ Tumour size (cm) } & \multirow[t]{4}{*}{0.832 NS } \\
\hline$\leq 4.3$ & 17 & 29 & \\
\hline$>4.3$ and $<7.8$ & 18 & 25 & \\
\hline$\geq 7.8$ & 19 & 11 & \\
\hline \multicolumn{3}{|l|}{ Tumour morphology } & \multirow[t]{3}{*}{0.748 NS } \\
\hline Massive & 34 & 22 & \\
\hline Diffuse & 14 & 16 & \\
\hline \multicolumn{3}{|l|}{ Portal vein tumour thrombosis } & \multirow[t]{3}{*}{$<0.001$} \\
\hline Absent & 52 & 29 & \\
\hline Present & 19 & 10 & \\
\hline \multicolumn{3}{|l|}{ Distant metastasis } & \multirow[t]{3}{*}{0.005} \\
\hline Absent & 55 & 25 & \\
\hline Present & 16 & 14 & \\
\hline \multicolumn{3}{|l|}{ History of HCC treatment } & 0.049 \\
\hline Absent & 29 & 18 & \\
\hline Present & 42 & 28 & \\
\hline
\end{tabular}


Table 2. Cont.

\begin{tabular}{|c|c|c|c|}
\hline Variables & Number & Median survival (day) & $p$ value (log-rank) \\
\hline \multicolumn{3}{|l|}{ Serum albumin $(g / l)$} & \multirow[t]{4}{*}{0.018} \\
\hline$\leq 2.5$ & 23 & 11 & \\
\hline$>2.5$ and $<3.2$ & 21 & 38 & \\
\hline$\geq 3.2$ & 20 & 20 & \\
\hline \multicolumn{3}{|l|}{ Serum total bilirubin $(\mu \mathrm{mol} / \mathrm{l})$} & \multirow[t]{4}{*}{$<0.001$} \\
\hline$\leq 1.2$ & 23 & 34 & \\
\hline$>1.2$ and $<2.5$ & 23 & 20 & \\
\hline$\geq 2.5$ & 24 & 10 & \\
\hline \multicolumn{3}{|l|}{ Serum AFP (ng/ml) } & \multirow[t]{4}{*}{0.173 NS } \\
\hline$\leq 420$ & 14 & 30 & \\
\hline$>420$ and $<15700$ & 15 & 15 & \\
\hline$\geq 15700$ & 15 & 18 & \\
\hline \multicolumn{3}{|l|}{ AST (U/I) } & \multirow[t]{4}{*}{0.079 NS } \\
\hline$\leq 63$ & 23 & 28 & \\
\hline$>63$ and $<144$ & 23 & 18 & \\
\hline$\geq 144$ & 24 & 13 & \\
\hline \multicolumn{3}{|l|}{$\operatorname{ALT}(\mathrm{U} / \mathrm{I})$} & \multirow{4}{*}{$0.228 \mathrm{NS}$} \\
\hline$\leq 32$ & 24 & 30 & \\
\hline$>32$ and $<62$ & 24 & 17 & \\
\hline$\geq 62$ & 22 & 14 & \\
\hline \multicolumn{3}{|l|}{ Haemoglobin $(\mathrm{g} / \mathrm{dl})$} & \multirow[t]{4}{*}{$0.125 \mathrm{NS}$} \\
\hline$\leq 7.7$ & 23 & 16 & \\
\hline$>7.7$ and $<10.0$ & 22 & 22 & \\
\hline$\geq 10.0$ & 25 & 30 & \\
\hline \multicolumn{3}{|l|}{ Prothrombin time (s) } & \multirow[t]{4}{*}{0.017} \\
\hline$\leq 14$ & 23 & 34 & \\
\hline$>14$ and $<40$ & 23 & 10 & \\
\hline$\geq 40$ & 23 & 22 & \\
\hline \multicolumn{3}{|l|}{ BUN (mg/dl) } & \multirow[t]{4}{*}{0.732 NS } \\
\hline$\leq 16.1$ & 24 & 25 & \\
\hline$>16.1$ and $<23.3$ & 24 & 20 & \\
\hline$\geq 23.3$ & 22 & 25 & \\
\hline \multicolumn{3}{|l|}{ CRE (mg/dl) } & \multirow[t]{4}{*}{0.974 NS } \\
\hline$\leq 0.8$ & 24 & 25 & \\
\hline$>0.8$ and $<1.3$ & 21 & 17 & \\
\hline$\geq 1.3$ & 25 & 18 & \\
\hline
\end{tabular}

$\mathrm{Cl}$ - confidence interval, TAE - transcatheter arterial embolization, Cons T - conservative treatment, NS - not significant, $\mathrm{HCC}$ - hepatocellular carcinoma, $\mathrm{Cl}$ - confident interval, AFP - $\alpha$-fetoprotein, AST - aspartate aminotransferase, ALT - alanine aminotransferase

prothrombin time were excluded from the analysis because they are included in the Child-Pugh classification. The multivariable analysis identified only the presence of distant metastasis as an independent factor determining lower overall survival ( $p=0.023$ ) (Table 3, Figure 2).
We performed an additional subanalysis including 55 patients without distant metastasis. A multivariable analysis showed that the presence of portal vein tumour thrombosis was the only significant independent prognostic factor $(p=0.015)$ (Table 4, Figure 3). 


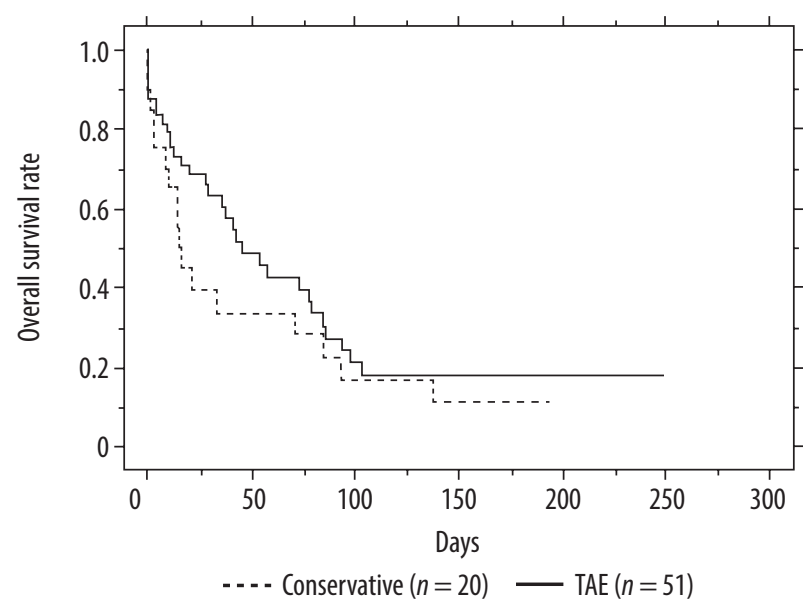

Figure 1. Cumulative survival rates in the conservative treatment (Cons $\mathrm{T}$ ) group ( $n=20)$ and in the transcatheter arterial embolization (TAE) group $(n=51)$. Difference between groups is not significant $(p=0.213)$

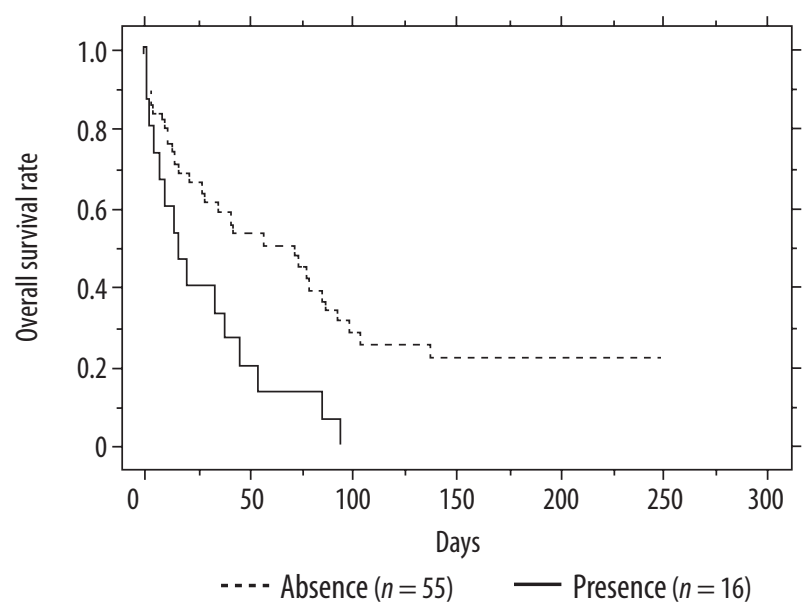

Figure 2. Cumulative survival rates in the absence of distant metastasis group $(n=55)$ and in the presence group $(n=16)$. Overall survival rate is significantly higher in the absence group than in the presence group $(p=0.005)$



Figure 3. Cumulative survival rates in the absence of portal vein tumor thrombosis group $(n=42)$ and in the presence group $(n=13)$ without distant metastasis. Overall survival rate is significantly higher in the absence group than in the presence group $(p<0.001)$
Table 3. Multivariable analysis searching for factors influencing overall survival

\begin{tabular}{|l|c|c|c|}
\hline Variables & $\begin{array}{c}\text { Hazard } \\
\text { ratio }\end{array}$ & $95 \% \mathrm{Cl}$ & $p$ value \\
\hline Sex (female) & 1.967 & $0.889-4.355$ & $0.095 \mathrm{NS}$ \\
\hline \begin{tabular}{l} 
Child-Pugh classification \\
\hline C
\end{tabular} & 2.208 & $0.574-8.491$ & $0.249 \mathrm{NS}$ \\
\hline B & 1.282 & $0.361-4.548$ & $0.700 \mathrm{NS}$ \\
\hline $\begin{array}{l}\text { Portal vein tumor thrombosis } \\
\text { (present) }\end{array}$ & 2.080 & $0.962-4.497$ & $0.063 \mathrm{NS}$ \\
\hline Distant metastasis (present) & 2.313 & $1.123-4.767$ & 0.023 \\
\hline $\begin{array}{l}\text { History of HCC treatment } \\
\text { (present) }\end{array}$ & 1.524 & $0.731-3.174$ & $0.261 \mathrm{NS}$ \\
\hline
\end{tabular}

Cl - confidence interval, NS - not significant, HCC - hepatocellular carcinoma

Table 4. Multivariable analysis including patients without distant metastasis

\begin{tabular}{|c|c|c|c|}
\hline Variables & $\begin{array}{l}\text { Hazard } \\
\text { ratio }\end{array}$ & $95 \% \mathrm{Cl}$ & $p$ value \\
\hline Sex (female) & 2.249 & $0.894-5.657$ & $0.085 \mathrm{NS}$ \\
\hline \multicolumn{4}{|l|}{ Child-Pugh classification } \\
\hline$C$ & 1.849 & $0.368-9.283$ & $0.455 \mathrm{NS}$ \\
\hline B & 1.379 & $0.303-6.260$ & $0.678 \mathrm{NS}$ \\
\hline $\begin{array}{l}\text { Portal vein tumour thrombosis } \\
\text { (present) }\end{array}$ & 2.896 & $1.222-6.864$ & 0.015 \\
\hline $\begin{array}{l}\text { History of HCC treatment } \\
\text { (present) }\end{array}$ & 1.482 & $0.616-3.564$ & $0.380 \mathrm{NS}$ \\
\hline
\end{tabular}

Cl - confidence interval, NS - not significant, HCC - hepatocellular carcinoma

\section{Discussion}

In the past, patients with spontaneously ruptured HCC were treated by various surgical procedures including perihepatic packing, suture plication of bleeding tumour, injection of absolute alcohol, hepatic artery ligation, and liver resection [2-13]. However, because those patients tend to have advanced disease and poor liver function from cirrhosis, invasive surgical interventions may not be tolerated. Thus, less invasive treatments such as TAE or conservative management are chosen in the majority of cases. TAE is considered to be highly effective in controlling haemorrhage due to ruptured HCC, and we expected that it would improve prognosis of the affected patients compared to conservative treatment. In fact, our results showed a better prognosis in the TAE group (MST $=28$ days) than in the Cons T group (MST = 16 days), but no significant difference in overall survival was revealed between the two groups $(p=0.213)$. An earlier retrospective study reported by Kirikoshi et al. showed a significantly better prognosis in patients treated with TAE (MST $=224.8$ days) than in those treated with conservative therapy $(\mathrm{MST}=13.1$ days) 
[11]. The discrepant results can possibly be accounted for by relatively better liver function in their patients than those in our study: percentage of child A patients was $24 \%$ and the mean of total bilirubin was $1.8 \mathrm{mmol} / \mathrm{l}$ in their study, while percentage of child A patients was $11 \%$ and the mean total bilirubin was $3.4 \mathrm{mmol} / \mathrm{l}$ in our study.

Despite a multitude of previous studies, no general consensus has been achieved on prognostic factors in patients with spontaneous rupture of HCC. In our multivariable analysis, the presence of distant metastasis was the only significant factor that was associated with lower overall survival (Table 3, Figure 2). Sixteen patients had distant metastasis (lung in 11 cases, lymph node in two cases, peritoneum in one case, adrenal gland in one case, and bone in one case), and their MST was 10 days (22 days in the absence group). Aoki et al. [6] analysed patients with spontaneous rupture of HCC and reported that stage IV group was associated with worse prognosis than the stage I-III group. Ueno et al. [14] reported that extrahepatic metastasis showed prognostic significance in multivariate analysis of unresectable HCC patients treated with transcatheter arterial chemoembolisation therapy. Distant metastasis of HCC has been regarded as a terminal event, and intrahepatic lesions were not actively treated in such cases [15]. However, some pervious reports showed that the metastatic lesion of HCC was a minor cause of death and the main cause of death was advanced intrahepatic lesions. In those reports, it was said that if a patient's liver status is good, treatment for liver and metastatic lesion may improve survival [16-19]. In general, ruptured HCC patient's liver status was mostly not good. In cases where distant metastasis is present, one should be careful about introducing TAE for treatment of ruptured HCC. Conservative treatment may be preferred in such cases.

Our univariate analysis revealed several additional items as possible prognostic factors. The presence of portal vein tumour thrombosis was significantly associated with lower overall survival (Table 2). MST of 19 patients with portal vein tumour thrombosis was 10 days while that of the absence group was 29 days. Okazaki et al. performed TAE in 38 patients with ruptured HCC. Although patients without portal vein tumour thrombus showed longer MST (133 days) than those with it (90 days), no significant difference in prognosis was demonstrated [13]. Nevertheless, our subanalysis including patients without distant metastasis $(n=55)$ identified it as an independent prognostic factor $(p=0.015)$ (Table 4, Figure 3 ). Thus, we consider that portal vein tumour thrombus could be a prognostic factor of ruptured HCC. Portal vein tumour thrombus was found in $12-39 \%$ of patients with HCC [1,20-22] and $18-57 \%$ of patient with ruptured HCC $[6,12,13]$. Yamada et al. [23] reported that TAE was contraindicated for patients with portal vein tumour thrombus, because TAE might increase the risk of ischaemic liver damage. On the other hand, some groups reported that TAE was a safe treatment method of HCC with peripheral portal vein tumour thrombus if the patient has good liver function [24-27]. In our study, 19 patients (26\%) had portal vein tumour thrombus, and TAE was conducted in 12 cases. There was no significant difference in the survival rate between TAE and conservative treatment $(p=0.1329)$. When central portal vein tumour thrombus is present, patients with ruptured HCC should be treated conservatively.

Tarantino et al. [5] reported that Child-Pugh A vs. B/C variables were statistically significant for overall survival of ruptured HCC patients. In agreement with their report, there was a significant difference in overall survival by Child-Pugh classification factor $(\mathrm{C}>\mathrm{A})$ in our univariate analysis (Table 2), although significant association was not confirmed in the multivariable analysis. This could be partly due to the small number of patients in the ChildPugh A group $(n=8)$.

The presence of hepatic encephalopathy, which is one of the criteria of Child-Pugh classification, was associated with lower overall survival in our univariate analysis (Table 2). Five patients had hepatic encephalopathy, and their MST was one day, whereas MST of 64 patients without it was 25 days. Kim et al. [7] studied 62 patients with ruptured HCC and found that early deaths were independently associated with the presence of hepatic encephalopathy.

Serum levels of albumin and total bilirubin are also included in the criteria of Child-Pugh classification. In the univariate analysis, lower albumin and higher bilirubin levels were found to be significantly associated with worse prognosis in ruptured HCC (Table 2). Okazaki et al. [13] reported that MST of the lower serum bilirubin value group $(\leq 3.0 \mathrm{mg} / \mathrm{dl})$ was 165 days and that of the higher value group ( $>3.0 \mathrm{mg} / \mathrm{dl}$ ) was 13 days, and that there was significant difference in the survival rate between lower and higher value groups. In our study, MST of the lower serum bilirubin value group $(\leq 3.0 \mu \mathrm{mol} / \mathrm{l})$ was 25 days and that of the higher serum bilirubin value group $(>3.0 \mu \mathrm{mol} / \mathrm{l})$ was 14 days.

There were some limitations in our study. Selection bias may exist due to the retrospective nature of this study. The Cons T group was relatively small.

\section{Conclusions}

The presence/absence of distant metastasis appears to be a prognostic factor in spontaneous rupture of HCC. In cases of absent metastasis, portal vein tumour thrombosis could influence the prognosis. Although TAE was associated with longer survival than conservative treatment, our data failed to provide evidence of a significant impact of TAE as the primary management of ruptured HCC. TAE should be conducted with caution, especially in patients with advanced disease.

\section{Conflict of interest}

The authors report no conflict of interest. 


\section{References}

1. Ikai I, Arii S, Okazaki M, et al. Report of the 17th nationwide follow-up survey of primary liver cancer in japan. Hepatol Res 2007; 37: 676-691.

2. Lai ECS, Choi TK, Wong J. Spontaneous ruptured hepatocellular carcinoma. Anappraisal of surgical treatment. Ann Surg 1989; 210 24-28.

3. Liu CL, Fan ST, Lo CM, et al. Management of spontaneous rupture of hepatocellular carcinoma: Single-center experience. J Clin Oncol 2001; 19: 3725-3732.

4. Lai ECH, Lau WY. Spontaneous rupture of hepatocellular carcinoma. Arch Surg 2006; 141: 191-198.

5. Tarantino L, Sordelli I, Calise F, et al. Prognosis of patients with spontaneous rupture of hepatocellular carcinoma in cirrhosis. Updates Surg 2011; 63: 25-30.

6. Aoki T, Kokubo N, Matuyama Y, et al. Prognostic impact of spontaneous tumor rupture in patients with hepatocellular carcinoma. Ann Surg 2014; 3: 532-142.

7. Kim YI, Ki HS, Kim MH, et al. Analysis of the clinical characteristics and prognosis factors of ruptured hepatocellular carcinoma. Korean J Hepatol 2009; 15: 148-158.

8. Feng Z, Xin SC, Kun H, et al. Treatment outcomes of spontaneous rupture of hepatocellular carcinoma with hemorrhagic shock: a multicenter study. SpringerPlus 2016; 5: 1101.

9. Pillai LV, Lim KF, Bujang MA, et al. Diagnosis and Management of ruptured hepatoma: signal center experience over 10 years. Med J Malaysia 2013; 68: 405-409.

10. Chearanai O, Plengvanit U, Asavanich C, et al. Spontaneous rupture of primary hepatoma: Report of 63cases with particular reference to the pathogenesis and rationale treatment by hepatic artery ligation. Cancer 1983; 51: 1532-1536.

11. Ong GB, Taw JL. Spontaneous rupture of hepatocellular carcinoma. BMJ 1972; 4: 146-149.

12. Kirikoshi H, Saito S, Yoneda M, et al. Outcomes and factors influencing survival in cirrhotic cases with spontaneous rupture of hepatocellular carcinoma: a multicenter study. BMC Gastroenterol 2009; 9: 29-38.

13. Okazaki M, Higashihara H, Koganemaru F, et al. Intraperitoneal hemorrhage from hepatocellular carcinoma: Emergency chemoembolization or embolization. Radiology 1991; 180: 647-651.
14. Ueno K, Miyazono N, Inoue H, et al. Transcatheter arterial chomoembolization therapy using lodized oil for patients with unresectable hepatocellular carcinoma. Cancer 2000; 88: 1574-1581.

15. Bruix j, Sherman M. Management of hepatocellular carcinoma. Hepatology 2005; 42: 1208-1236.

16. Katyal S, Oliver JH, Peterson MS, et al. Extrahepatic metastasis of heoatocellular carcinoma. Radiology 2000; 216: 698-703.

17. Natsuizaka M, Omura T, Akaike T, et al. Clinical features of hepatocellular carcinoma with extrahepatic metastases. J Gastoroenterol Hepatol 2005; 20: 1781-1787.

18. Uka k, Aikata H, Takaki S, et al. Clinical ferature and prognosis of patients with extrahapatic metastasis from hepatocellularcarcinoma. World J Gastroenterol 2007; 13: 414-420.

19. Uchino K, Tateishi R, Shiina S, et al. Hepatocellular carcinoma with extrahepatic metastasis. Cancer 2011; 117: 4475-4487.

20. Marrero JA, Fontana RJ, Barrat A, et al. Prognosis oh Hepatocellular carcinoma: Compariso of 7 staging systems in an American cohort. Hepatology 2005; 41: 707-716.

21. Ninagawa M, Makuuchi M. Treatment of hepatocellular carcinoma accompanied by portal vein tumor thrombus. World J Gastroenterol 2006; 12: 7561-7567.

22. Jia L, Kiryu S, Watadani T, et al. Prognosis of hepatocellular carcinoma with portal vein tumor thrombus; Assessment based on clinical and computer tomography characteristics. Acta Med Okayama 2012; 66: 131-141.

23. Yamada R, Sato M, Kawabata M, et al. Hepatic artery embolization in 120 patients with unresectable hepatoma. Radiology 1983; 148: 397-401.

24. Chung JW, Park JH, Han JK, et al. Hepatocellular carcinoma and portal vein invasion : result of treatment with trancecatheter oily chemoembolization. AJR Am J Roentgenol 1995; 8: 315-321.

25. Yen FS, Wu JC, Kuo BI, et al. Transcatheter arterial embolization for hepatocellular carcinoma with portal vein thrombosis. J Gastroenterol Hepatol 1995; 10: 237-240.

26. Furuse J, Iwasaki M, Yoshino M, et al. Hepatocellular carcinoma with portal vein tumor thrombus: embolization of arterioportal shunts. Radiology 1997; 204: 787-790.

27. Yang MY, Jeong SW, Kim DK, et al. Treatment of hepatocellular carcinoma with potrtal vein thrombosis by Sorafenib combined with hepatis arterial infusion chemotherapy. Gut Liver 2010; 4: 423-427. 